\title{
METHODS FOR IMPROVING EFFICIENCY OF LINEAR INDUCTION MOTOR FOR URBAN TRANSIT
}

\author{
Nobuo FUJII, Toshiyuki HOSHI and Yuichi TANABE
}

\author{
Department of Electrical and Electronic Systems Engineering \\ Faculty of Information Science and Electrical Engineering \\ Kyushu University \\ fujii@ees.kyushu-u.ac.jp
}

\begin{abstract}
To improve the efficiency of the linear induction motors (LIMs) for transportation, the compensation of end effect for LIM with the restriction of length and the long LIM with small end effect essentially are discussed respectively. Based on the proposed concept, the compensation method of the magnet rotator type and AC coil type of compensators are developed respectively. The utility is not yet confirmed. As for the long LIM with length of $10 \mathrm{~m}$, the analysis shows that the efficiencies are about $85 \%$ at $40 \mathrm{~km} / \mathrm{h}$ and above $90 \%$ at $360 \mathrm{~km} / \mathrm{h}$ respectively.
\end{abstract}

\section{INTRODUCTION}

In a part of new type transit, linear induction motors (LIMs) have been used as a direct electromagnetic drive device without adhesion. In Japan, the LIM-driven train has been used in the subway in some large cities, as the LIM reduces the construction cost of tunnel because the thin shape makes the sectional area of tunnel small and the large gradability enables the minimum length of the route. In another case, the LIMs are used in magnetic levitation vehicle called HSST which will be used for the urban or intercity transit, and in an air suspended vehicle with low floor which aims to be used for a personal rapid transit.

On these LIM-driven trains, there is the problem of large power consumption. That is, the efficiency is not satisfactory. In the induction type motor, the efficiency depends on the operating slip and the small slip is required fundamentally for the high efficiency. On the other hand, the LIM has its own end effect which decreases the efficiency and power factor in the small slip region. The influence of end effect becomes serious as the speed increases. That is, the essential measure for high efficiency is to overcome the end effect, which is a long-pending object.

Under the condition that there is restriction on the length of LIM, the compensation of end effect is the only method for remarkable improve of the characteristics. The compensating winding method was proposed previously [1], but it was not effective. The authors have proposed the new type of end effect compensator [2]. The proposed method is based on the new concept that the end effect can be compensated only by supplying the eddy current synchronizing with the LIM frequency in front of LIM, which was derived from the previous study.

In the paper, as examples of the way to realize the theory of compensation, the magnet rotator with permanent magnets as a mechanical rotating type and the AC coil type with concentrated winding as a static compensator are discussed.

On the other hand, the long LIM is basic to the small end effect in case we can use the space along the vehicle length. In the paper, the use of an onboard primary-member type LIM with long armature core of $10 \mathrm{~m}$ is studied analytically.

\section{LIM WITH END EFFECT COMPENSATOR}

The end effect compensator is attached in front of the entry end of primary of LIM to compensate the dynamic entry end effect.

\subsection{Magnet Rotator Type of Compensator}

Fig. 1 shows the magnet rotator type of end effect 
compensator installed at the front of armature of LIM. The magnet rotator has the poles of permanent magnets, and the rotating speed $n_{s}$ (rps) is synchronized with the frequency of LIM. That is,

$$
n_{s}=2 f_{1} / p
$$

where, $f_{1}(\mathrm{~Hz})$ is the frequency of current in the primary winding of LIM and $p$ the number of poles of the magnet rotator. The rotating speed is constant for the slip of LIM. This type of compensator has the merit that there is little power consumption except the joule loss by the eddy current in the secondary conducting plate, and it is a compact size with large magnetomotive force and without ohmic loss. The phase adjustment between the compensator and the LIM can be done by controlling the inverter of LIM in the practical use.

As it is very difficult to analyze of LIM with the magnet rotator type compensator exactly, the rotator is replaced by the equivalent static winding with rotating field [2]. In the procedure, the 3-D dynamic electromagnetic analysis (Package ELF/MAGIC) for the real model of magnet rotator, and the 2-D finite element method (FEM: Package ANSYS) for the equivalent model were used. The quasi-3D analysis is done by using the 2-D FEM for the model of LIM with the compensator, considering with the effect of transverse direction by using Russell-Norsworthy coefficient.

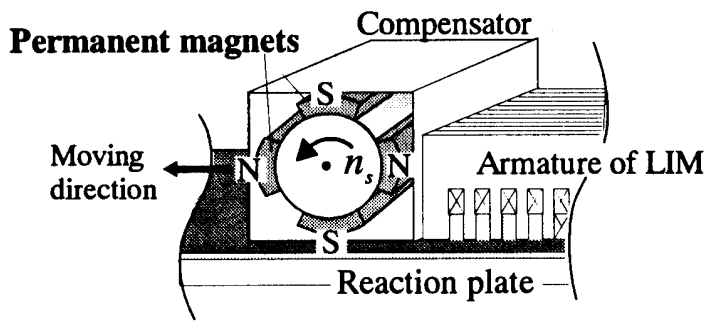

Fig. 1 Magnet rotator type of compensator.

Table 1 Example of LIM parameters.

\begin{tabular}{l|c|c}
\hline \multicolumn{1}{c|}{ Name } & Notation & Value \\
\hline Rated frequency & $f_{1}$ & $22.0 \mathrm{~Hz}$ \\
Rated current & $I_{1}$ & $208 \mathrm{~A}$ \\
Rated slip & $s$ & 0.17 \\
Number of poles & $p$ & 8 \\
Length of armature core & $L_{a}$ & $2,476 \mathrm{~mm}$ \\
Width of armature core & $h$ & $300 \mathrm{~mm}$ \\
Pole pitch & $\tau$ & $280.8 \mathrm{~mm}$ \\
\hline Mechanical clearance & $g$ & $12 \mathrm{~mm}$ \\
\hline Secondary conducting plate & & \\
$\quad$ Conductivity & $\sigma_{2}$ & $4.93 \times 10^{7} \mathrm{~S} / \mathrm{m}$ \\
$\quad$ Thickness & $d_{2}$ & $5.0 \mathrm{~mm}$ \\
$\quad$ Width & $h_{2}$ & $360 \mathrm{~mm}$ \\
Secondary back iron plate & & \\
$\quad$ Thickness & $d_{1}$ & $22 \mathrm{~mm}$ \\
$\quad$ Width & $h_{1}$ & $360 \mathrm{~mm}$ \\
\hline
\end{tabular}

Table 2 Numerals of magnet rotator type of compensator.

\begin{tabular}{c|cc}
\hline Specification data & \multicolumn{2}{|c}{ Value } \\
\hline Radius of rotator & 156 & $\mathrm{~mm}$ \\
Length of magnet & 143 & $\mathrm{~mm}$ \\
Number of pole of compensator & 4 & \\
Thickness of magnet (rare earth magnet) & 52 & $\mathrm{~mm}$ \\
Coercivity of magnet & 995 & $\mathrm{kA} / \mathrm{m}$ \\
Remanent magnetic flux density & 1.36 & $T$ \\
\hline
\end{tabular}

The characteristics of LIM with the magnet rotator type of compensator are studied on the parameters as shown in Table 1 and Table 2. The parameter of LIM is similar to that of the subway vehicle in Tokyo.

Fig. 2 shows the analytical characteristics of LIM when the optimal phase of current for compensation is supplied. The thrust and efficiency of LIM increase by means of the compensator respectively. It is very difficult to analyze the overall efficiency at the current stage. We are preparing for the experimental study using the test facility shown in Fig. 3.

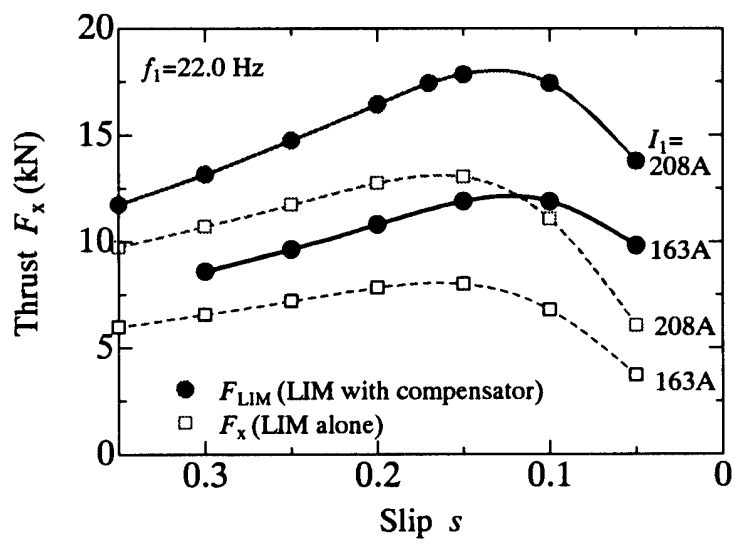

(a) Thrust

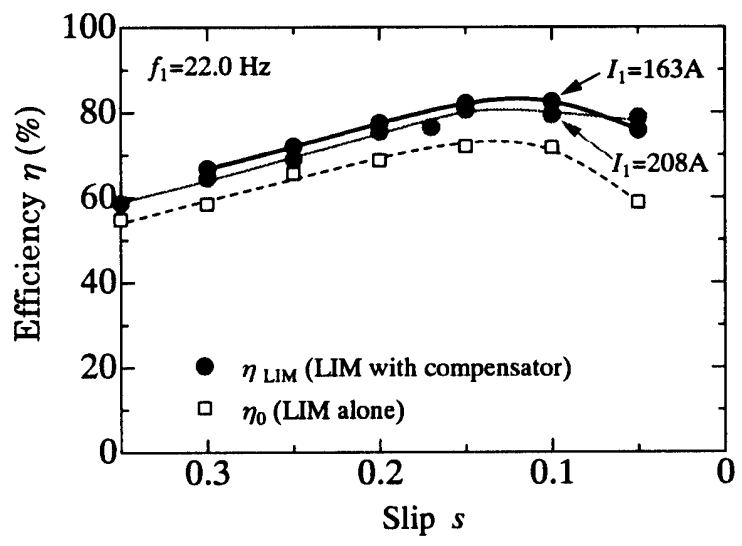

(b) Efficiency

Fig. 2 Characteristics of LIM with the magnet rotator type of compensator. 


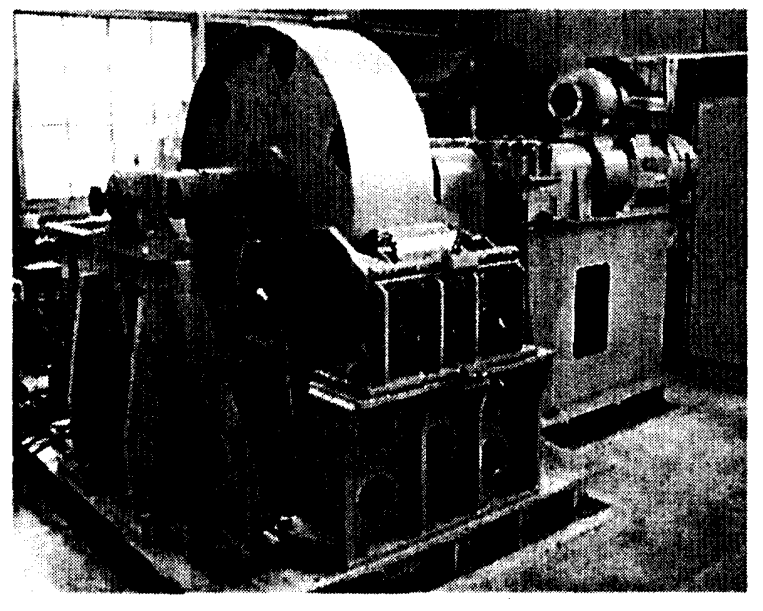

Fig. 3 Test facility of LIM (rotating secondary type) with the magnet rotator type of compensator.

\subsection{Single-phase AC Coil Type of Compensator}

Fig. 4 shows the compensator using $\mathrm{AC}$ coils to avoid the mechanical rotation and to enable the adjustment of magnetomotive force (MMF) of compensator, although it has the problem of poor power factor in the compensator due to its own end effect. The frequency of compensator current is equal to that of LIM.

In this model, it is not difficult to analyze the overall characteristics of LIM with the compensator, compared with the magnet rotator type. The quasi-3D analysis using 2-D FEM is done to analyze the model. As a numerical example, the LIM of Table 1 and the compensator shown in Table 3 are used.

The single-phase AC coil type of compensator generally generates the negative thrust in the region due to its own end effect. Fig. 5 is the characteristics of LIM with the coil type of compensator, in which the pole-pitch and pole-length of the compensator are selected optimally for the minimum braking thrust of compensator respectively.

The thrust characteristics of Fig. 5(a) shows that the coil type has the ability to compensate the end effect and the

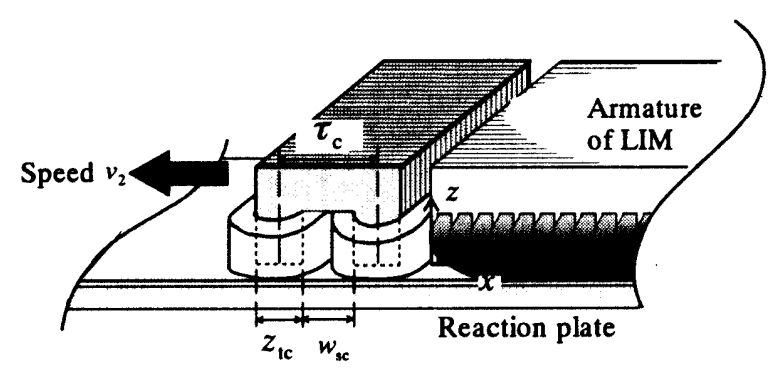

Fig. 4. AC Coil Type of Compensator.
Table 3 Design example of two-coil type compensator.

\begin{tabular}{l|c|c}
\hline \multicolumn{1}{c|}{ Name } & Notation & Value \\
\hline Supply frequency & & $22.0 \mathrm{~Hz}$ \\
Length of (core) pole & $z_{t c}$ & $200 \mathrm{~mm}$ \\
Width of (core) pole & & $300 \mathrm{~mm}$ \\
Thickness of coil & & $46 \mathrm{~mm}$ \\
Distance between poles & $w_{s c}$ & $100 \mathrm{~mm}$ \\
Pole pitch & $\tau_{c}$ & $300 \mathrm{~mm}$ \\
\hline
\end{tabular}

MMF of compensator increases the overall thrust lineally. Fig. 5(b) shows the overall efficiency considering both LIM and compensator. The overall efficiency decreases when the MMF of compensator is large, because the copper loss in the winding becomes large. The maximum value of overall efficiency is large attractively. The accuracy of computation is not yet confirmed because the numerical solution of FEM needs a very large number of elements for this model.

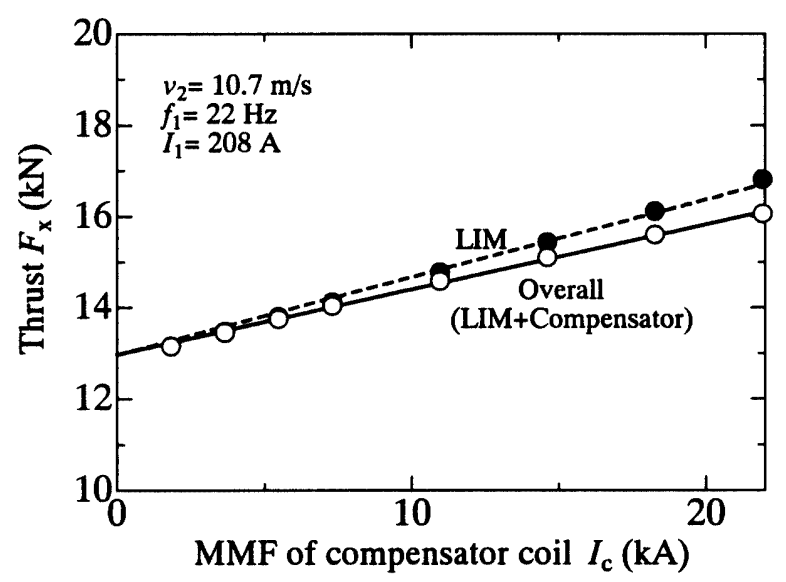

(a) Thrust

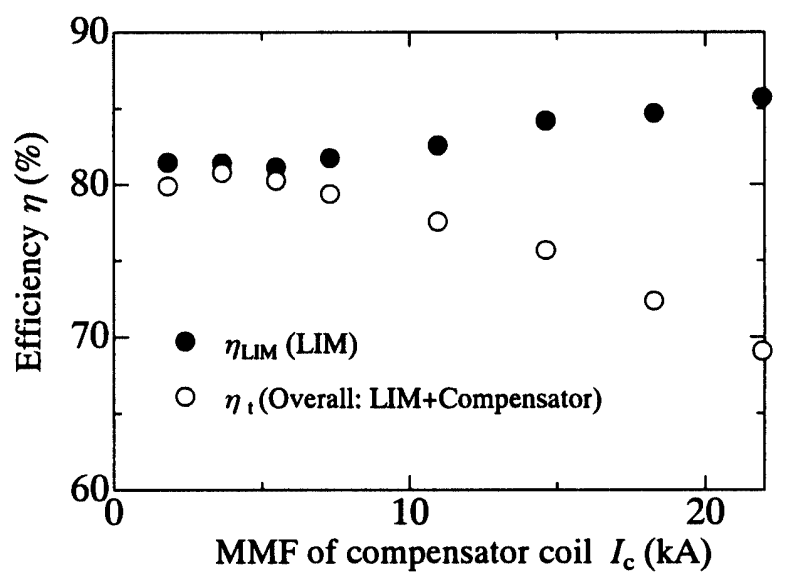

(b) Efficiency

Fig. 5 Characteristics of LIM with the coil type of compensator. 


\subsection{Consideration of Overall Efficiency}

The overall characteristics of the LIM and compensator must be studied for the net improvement by the compensator. The overall efficiency is expressed as:

$$
\eta_{t}=v_{2}\left(F_{L I M}+F_{C}\right) /\left(P_{L I M}+P_{C}\right)
$$

where, $F_{L I M}$ is the thrust in LIM region and it is not the thrust at LIM alone, $v_{2}$ the speed of LIM, $F_{C}$ the thrust in the compensator region, $P_{L I M}$ the input power of LIM, $P_{C}$ the input power of compensator. For the magnet rotator type of compensator, $P_{C}$ is:

$$
P_{c}=\omega_{c} T_{c}+P_{d l}=2 \pi n_{s} T_{c}+P_{d l}
$$

where, the $T_{c}$ is the torque and $P_{d l}$ the loss in driving mechanism of the compensator. At the current stage, we don't yet get the analytical technique to estimate $T_{c}$ in this model.

We discuss about the efficiency on the condition neglecting the iron loss. The efficiency in case of LIM alone is defined by:

$$
\eta_{0}=F_{x} v_{2} /\left(F_{x} v_{2}+P_{L 1}+P_{L 2}\right)
$$

where, $F_{x}$ is the thrust of LIM, $P_{L 1}$ the copper loss of the primary winding of LIM and $P_{L 2}$ the copper loss in the secondary member (reaction rail). The overall efficiency of the LIM and compensator is expressed:

$$
\begin{aligned}
\eta_{t}= & k_{t} F_{x} v_{2} /\left(k_{t} F_{x} v_{2}+P_{L 1}+k_{L} P_{L 2}+P_{C 1}+P_{C 2}\right) \\
& k_{t} F_{x}=F_{L I M}+F_{C}
\end{aligned}
$$

where, $k_{t}$ is the thrust ratio to that of LIM alone, $k_{L}$ the ratio of secondary copper loss in the LIM region to that of LIM alone, $P_{C 2}$ the secondary copper loss (in the reaction plate) in the compensator region. $P_{C 1}$ is the copper loss of the winding in the coil type of compensator, or it is $P_{d l}$ in the rotator type of compensator. $P_{L 1}$ is constant for the LIM drive with constant primary current. Equation (4) can be written

$$
\begin{aligned}
\eta_{t} & =F_{x} v_{2} /\left\{\left(F_{x} v_{2}+P_{L 1}+P_{L 2}\right)+\Delta P\right\} \\
\Delta P & =\frac{1}{k_{t}} P_{C 1}-\left(1-\frac{1}{k_{t}}\right) P_{L 1}+\frac{1}{k_{t}} P_{C 2}-\left(1-\frac{k_{L}}{k_{t}}\right) P_{L 2}
\end{aligned}
$$

From Equation (6) and (7), the condition for $\eta_{t}>\eta_{0}$ is $\Delta P<0$, that is

$$
\left(k_{t}-1\right) P_{L 1}\left(1-\frac{1}{k_{t}-1} \frac{P_{C 1}}{P_{L 1}}\right)+\left(k_{t}-k_{L}\right) P_{L 2}\left(1-\frac{1}{k_{t}-k_{L}} \frac{P_{C 2}}{P_{L 2}}\right)>0
$$

The sufficient condition for $\eta_{t}>\eta_{0}$ is

$$
\left(k_{t}-1\right) P_{L 1}>P_{C 1} \text { and }\left(k_{t}-k_{L}\right) P_{L 2}>P_{C 2}
$$

\section{LIM WITH 10m LONG ARMATURE}

Recently, the prototype of air-levitated vehicle installed several LIMs with total length of about $10 \mathrm{~m}$ has been constructed [3]. In the paper, we study the LIM with long armature core of $10 \mathrm{~m}$ on the assumption that we can realize this LIM.

The LIMs are designed to have the high efficiency by using the design equations proved by the experimental study [4]. The design examples for rated speed of $40 \mathrm{~km} / \mathrm{h}$ and $360 \mathrm{~km} / \mathrm{h}$ are shown in Table 4 and Table 5 respectively. The rated thrust is fixed with $30 \mathrm{kN}$ at the rated speed. Fig. 6 and Fig. 7 are the characteristics of LIMs shown in table 4 and table 5 respectively. The number of poles or the pole pitch is not sensitive for the efficiency, and sensitive only for the normal force. The power factor is not good, compared with that of rotating machine, because the width of reaction plate is restricted in spite of the large air gap. The computed results show that the efficiencies are about $85 \%$ at $40 \mathrm{~km} / \mathrm{h}$ and above $90 \%$ at $360 \mathrm{~km} / \mathrm{h}$ respectively.

\section{CONCLUSION}

For LIM with the restriction of length, the compensation method of the magnet rotator type and the AC coil type of compensators are discussed respectively. Those utility are not yet confirmed. When we can use the $10 \mathrm{~m}$ long LIM, the efficiencies will be about $85 \%$ at $40 \mathrm{~km} / \mathrm{h}$ and above $90 \%$ at $360 \mathrm{~km} / \mathrm{h}$ respectively, compared with about $75-76 \%$ of the existing LIM.

This work has been supported in part by the Grant-in-Aid for Scientific Research (B) from Japan Society for the Promotion of Science (No. 15360150).

\section{REFERENCES}

[1] S. Yamamura, Theory of Linear Induction Motors, Second Edition, University of Tokyo Press, 1978, pp.111-123, 204-206

[2] N. Fujii, T. Harada, Y. Sakamoto, T. Kayasuga: "Compensation method for end effect of linear induction motor", T. IEE of Japan, Vol. 122-D, No. 4, pp.330-337 (2002-4)(in Japanese), Electrical Engineering in Japan, Vol. 143, No.3, pp.58-67 (May 2003)

[3] R. Shindoh, T. Mizuma: "Evaluation of Air Suspended LIM Driven Transit System", Proc. of $6^{\text {th }}$ Int. Sympo. on Magnetic Suspension Technology, pp.345-348, Turin, Italy (2001-10)

[4] S. Nonaka, N. Fujii, T. Watanabe, Y. Kojima: "Experimental Study on Characteristics of Linear Induction Motor for Urban Transit", T. IEE of Japan, Vol. 108-D, No. 5, pp.477-484 (1988-5)(in Japanese) 
Table 4 Design parameter of $10 \mathrm{~m}$ long LIMs for urban transit.

\begin{tabular}{|c|c|c|c|c|}
\hline \multirow{2}{*}{ Name } & $\mathrm{P} 22 \mathrm{u}$ & $\mathbf{P} 28 \mathrm{u}$ & P34u & \multirow{2}{*}{ Unit } \\
\hline & \multicolumn{3}{|c|}{ Value } & \\
\hline \multicolumn{5}{|l|}{ Rated } \\
\hline Thrust & 30 & 30 & 30 & $\mathrm{kN}$ \\
\hline Speed & 40 & 40 & 40 & $\mathrm{~km} / \mathrm{h}$ \\
\hline Frequency & 13.8 & 17.2 & 20.9 & $\mathrm{~Hz}$ \\
\hline Slip & 0.068 & 0.070 & 0.077 & \\
\hline Phase current & 252 & 247 & 286 & A \\
\hline Phase voltage & 1124 & 1104 & 960 & $\mathrm{~V}$ \\
\hline \multicolumn{5}{|l|}{ Primary } \\
\hline Core length & 10.0 & 10.0 & 10.0 & $\mathbf{m}$ \\
\hline width & 300 & 300 & 300 & $\mathrm{~mm}$ \\
\hline height & 147 & 129 & 116 & $\mathrm{~mm}$ \\
\hline Slot pitch & 36 & 29 & 32 & $\mathrm{~mm}$ \\
\hline Slot depth & 80 & 80 & 80 & $\mathrm{~mm}$ \\
\hline Tooth width & 11 & 11 & 11 & $\mathrm{~mm}$ \\
\hline Number of phases & 3 & 3 & 3 & \\
\hline Number of poles & 22 & 28 & 34 & \\
\hline Pole pitch & 432 & 348 & 288 & $\mathrm{~mm}$ \\
\hline Slots/pole/phase & 4 & 4 & 3 & \\
\hline Turns/coil & 5 & 4 & 4 & \\
\hline Series turns & 440 & 448 & 408 & \\
\hline Current density & 2.38 & 2.59 & 2.57 & $\mathrm{~A} / \mathrm{mm}^{2}$ \\
\hline Resistance & 0.137 & 0.145 & 0.105 & 0 \\
\hline Leakage reactance & 0.649 & 0.799 & 0.715 & $\mathrm{O}$ \\
\hline $\begin{array}{l}\text { Mechanical } \\
\text { clearance }\end{array}$ & 12 & 12 & 12 & $\mathrm{~mm}$ \\
\hline \multicolumn{5}{|l|}{ Secondary } \\
\hline $\begin{array}{l}\text { Copper plate } \\
\text { Resistivity }\end{array}$ & & $2.1 \times 10^{-8}$ & & $\mathrm{Om}$ \\
\hline Thickness & 5 & 5 & 5 & $\mathrm{~mm}$ \\
\hline Width & 360 & 360 & 360 & $\mathrm{~mm}$ \\
\hline Overhang & 30 & 30 & 30 & $\mathrm{~mm}$ \\
\hline $\begin{array}{c}\text { Back iron plate } \\
\text { Resistivity }\end{array}$ & & $9.0 \times 10^{-8}$ & & $\mathrm{Om}$ \\
\hline Thickness & 25 & 25 & 25 & $\mathrm{~mm}$ \\
\hline Width & 360 & 360 & 360 & $\mathrm{~mm}$ \\
\hline
\end{tabular}

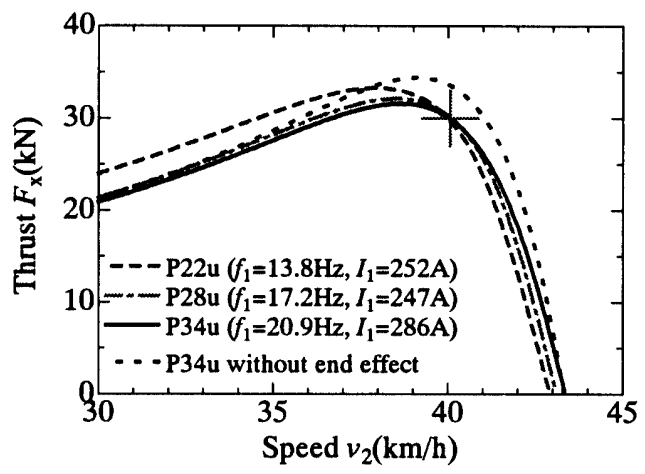

(a) Thrust

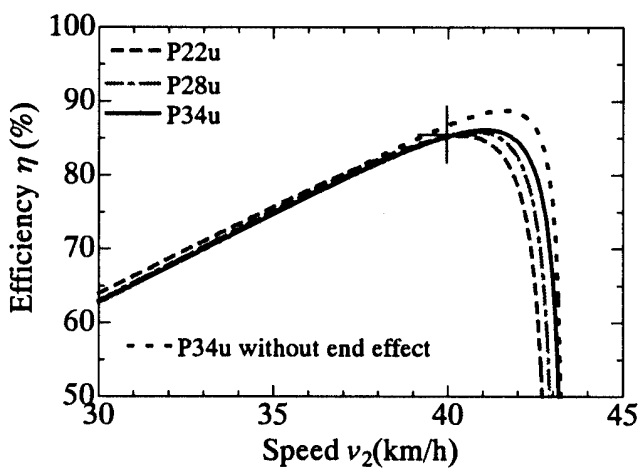

(b) Efficiency

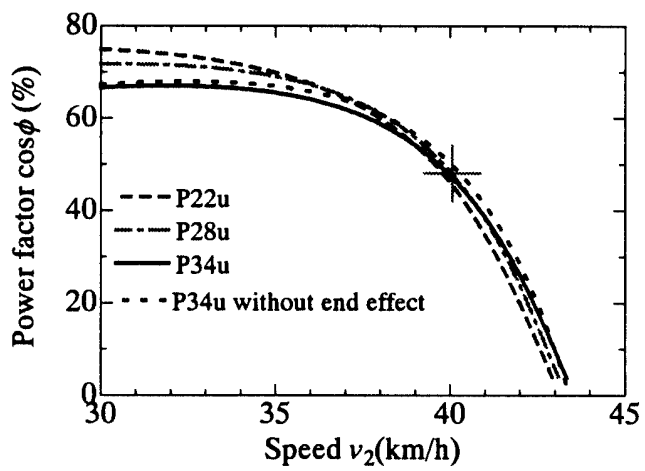

(c) Power factor

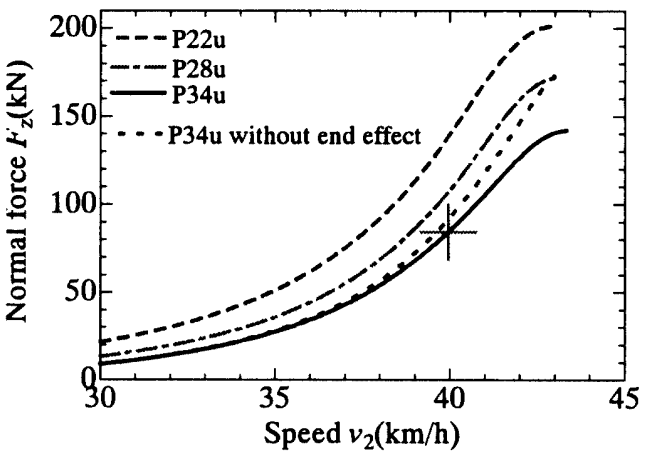

(d) Normal force

Fig. 6 Slip (speed) characteristics of $10 \mathrm{~m}$ long LIM for rated speed of $40 \mathrm{~km} / \mathrm{h}$. 
Table 5 Design parameter of $10 \mathrm{~m}$ long LIMs for high-speed.

\begin{tabular}{|c|c|c|c|c|}
\hline \multirow{2}{*}{ Name } & $\mathrm{P} 22 \mathrm{~h}$ & $\mathrm{P} 28 \mathrm{~h}$ & P34h & \multirow{2}{*}{ Unit } \\
\hline & \multicolumn{3}{|c|}{ Value } & \\
\hline \multicolumn{5}{|l|}{ Rated } \\
\hline Thrust & 30 & 30 & 30 & $\mathrm{kN}$ \\
\hline Speed & 360 & 360 & 360 & $\mathrm{~km} / \mathrm{h}$ \\
\hline Frequency & 122 & 152 & 183 & $\mathrm{~Hz}$ \\
\hline Slip & 0.052 & 0.052 & 0.052 & \\
\hline Phase current & 1465 & 1299 & 1516 & A \\
\hline Phase voltage & 1300 & 1371 & 1237 & $\mathrm{~V}$ \\
\hline \multicolumn{5}{|l|}{ Primary } \\
\hline Core length & 10.0 & 10.0 & 10.0 & $\mathbf{m}$ \\
\hline width & 300 & 300 & 300 & $\mathrm{~mm}$ \\
\hline height & 122 & 113 & 108 & $\mathrm{~mm}$ \\
\hline Slot pitch & 36 & 29 & 32 & $\mathrm{~mm}$ \\
\hline Slot depth & 80 & 80 & 80 & $\mathrm{~mm}$ \\
\hline Tooth width & 11 & 11 & 11 & $\mathrm{~mm}$ \\
\hline Number of phases & 3 & 3 & 3 & \\
\hline Number of poles & 22 & 28 & 34 & \\
\hline Pole pitch & 432 & 348 & 288 & $\mathrm{~mm}$ \\
\hline Slots/pole/phase & 4 & 4 & 3 & \\
\hline Turns/coil & 1 & 1 & 1 & \\
\hline Series turns & 88 & 112 & 102 & \\
\hline Current density & 2.76 & 2.45 & 2.86 & $\mathrm{~A} / \mathrm{mm}^{2}$ \\
\hline Resistance & 6.2 & 8.5 & 6.1 & $\mathrm{mO}$ \\
\hline Leakage reactance & 0.294 & 0.390 & 0.341 & $\mathrm{O}$ \\
\hline $\begin{array}{l}\text { Mechanical } \\
\text { clearance }\end{array}$ & 12 & 12 & 12 & $\mathrm{~mm}$ \\
\hline \multicolumn{5}{|l|}{ Secondary } \\
\hline $\begin{array}{c}\text { Aluminum plate } \\
\text { Resistivity }\end{array}$ & \multicolumn{3}{|c|}{$3.10 \times 10^{-8}$} & $\mathrm{Om}$ \\
\hline Thickness & 5 & 5 & 5 & $\mathrm{~mm}$ \\
\hline Width & 360 & 360 & 360 & $\mathrm{~mm}$ \\
\hline Overhang & 30 & 30 & 30 & $\mathrm{~mm}$ \\
\hline $\begin{array}{c}\text { Back iron plate } \\
\text { Resistivity }\end{array}$ & \multicolumn{3}{|c|}{$19.0 \times 10^{-8}$} & $\mathrm{Om}$ \\
\hline Thickness & 25 & 25 & 25 & $\mathrm{~mm}$ \\
\hline Width & 360 & 360 & 360 & $\mathrm{~mm}$ \\
\hline
\end{tabular}

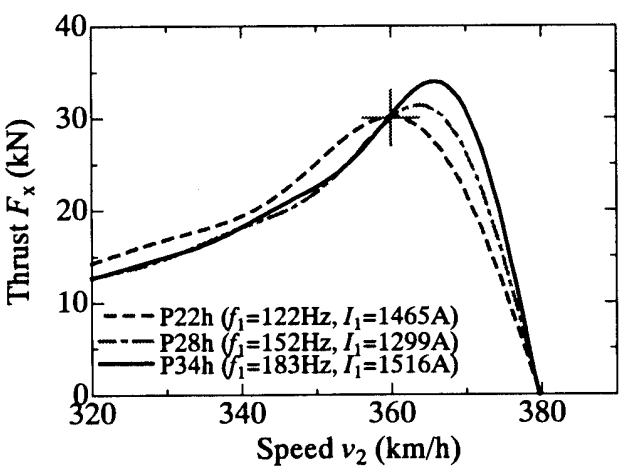

(a) Thrust

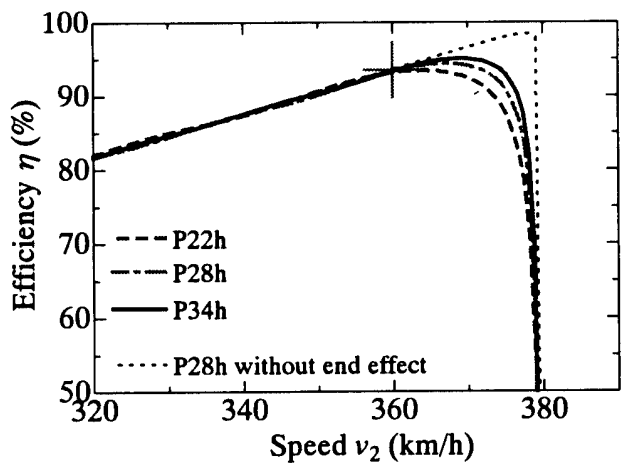

(b) Efficiency

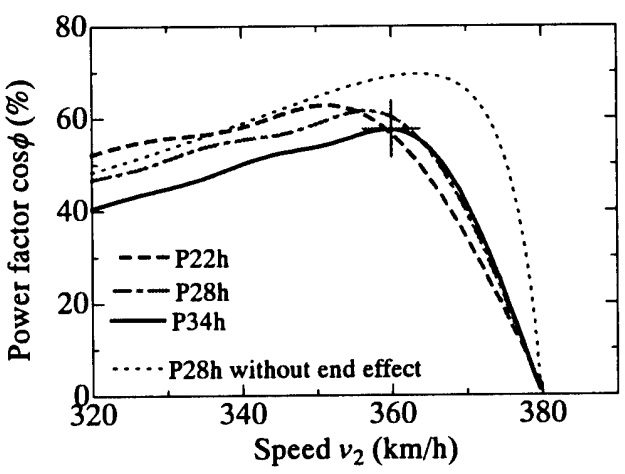

(c) Power factor

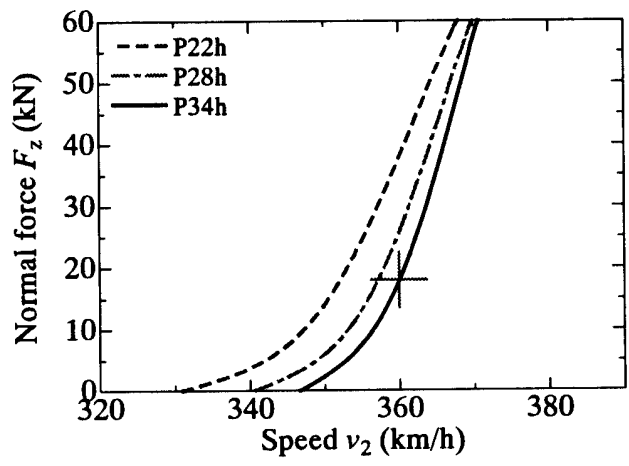

(d) Normal force

Fig. 7 Slip (speed) characteristics of 10m long LIM for rated speed of $360 \mathrm{~km} / \mathrm{h}$. 